\title{
INCREASED FETAL NUCHAL TRANSLUCENCY THICKNESS AND NORMAL KARYOTYPE: PRENATAL AND POSTNATAL FOLLOW-UP
}

Fátima Aparecida Targino Saldanha ${ }^{1}$, Maria de Lourdes Brizot ${ }^{2 *}$, Edécio Armbruster de Moraes ${ }^{3}$, Lilian M Lopes ${ }^{4}$, Marcelo Zugaib5 ${ }^{4}$

Study conducted at the Obstetric Clinic, Hospital das Clínicas, School of Medicine, Universidade de São Paulo - Department of Obstetrics and Gynecology

*Correspondence:

Av. Dr. Enéas de Carvalho

Aguiar, 255 - Instituto

Central - $10^{\circ}$ Andar -

Obstetrícia

São Paulo - SP

05403-000

mlbrizot@uol.com.br

\begin{abstract}
OвJEctive: The aim of this study was to evaluate prenatal and postnatal outcomes of fetuses with increased nuchal translucency thickness (NT) and normal karyotype.

METHODs: Two hundred seventy-five fetuses with increased NT were submitted to karyotyping analysis, serial ultrasound scans, echocardiography and postnatal clinical and genetic evaluation at the Division of Fetal Medicine of the Obstetric Outpatient Clinic of Universidade de São Paulo.

Results: The karyotype was abnormal in $14.2 \%$ of the cases and normal in $85.8 \%$. In cases with normal karyotype, $24.7 \%$ presented structural abnormalities in the second-trimester ultrasound scan, and one third showed major malformations, $35.7 \%$ of which consisted of heart defects. Adverse pregnancy outcome such as miscarriages, intrauterine and neonatal deaths occurred in $10.2 \%$ of cases. Postnatal follow-up was established for $72.7 \%$ of infants, and abnormalities were observed in $14.8 \%$ of them. Chances of having a live and healthy infant decreased with increased NT thickness, corresponding to $37.5 \%$ for NT equal to or greater than $4.5 \mathrm{~mm}$.

ConcLusion: In cases with increased NT thickness and normal karyotype, the frequency of fetal malformations, especially heart defects, adverse pregnancy outcomes and postnatal abnormalities is related to NT thickness.
\end{abstract}

KEYWORDS: First trimester of pregnancy. Chromosomal aberrations. Ultrasound scan. Congenital heart defects. Nuchal translucency measurement.

\section{INTRODUCTION}

Increased nuchal translucency (NT) is a common phenotypic expression in chromosomally abnormal fetuses and in those with structural malformations and genetic syndromes. ${ }^{1}$ Possible mechanisms whereby these increases may occur include cardiac dysfunctions associated with heart defects and large arteries, head and neck venous congestion, abnormal composition of the extracellular matrix, lymphatic drainage failure caused by abnormal or late development of the lymphatic system, limited fetal movements, fetal anemia or hypoproteinemia and congenital infections. ${ }^{2}$

Increased NT is found in $4.4 \%$ of chromosomally normal fetuses, which are at a significant risk of fetal malformations, skeletal dysplasia, genetic syndromes and delayed brain development. The number of anomalies knowingly associated with increased NT is not fully known, but there is a large group of fetuses with increased NT that eventually develop into healthy neonates. ${ }^{3}$ Therefore, increased NT per se is not a fetal abnormality, given that around $70,50,30$ and $15 \%$ of fetuses with NT of 3.5 to $4.4 \mathrm{~mm}, 4.5$ to $5.4 \mathrm{~mm}, 5.5$ to $6.4 \mathrm{~mm}$ and equal to or greater than $6.5 \mathrm{~mm}$ in thickness, respectively, are born healthy, after chromosomal defects have been ruled out.1,4

The prevalence of fetal abnormalities and adverse pregnancy outcomes increases exponentially with the thickness of NT, especially when it becomes as thick as $3.5 \mathrm{~mm} .{ }^{1,5}$ The number of major fetal malformations (FM) rises from $2.5 \%$ to nearly $45 \%$ and the miscarriage rate and fetal death go from 8 to $80 \%$ when NT increases by $6.5 \mathrm{~mm}$ or more between the 95th and 99th percentiles, respectively. ${ }^{1,2,4,6}$

It is universally acknowledged in the literature that increased NT is a marker of adverse pregnancy outcomes, both for chromosomally abnormal fetuses and for those with normal karyotypes. However, few studies have focused on the follow-up of liveborn infants with history of increased fetal NT, normal karyotypes and normal ultrasound scans. ${ }^{7}$ Bekker $^{3}$ assessed nine studies ${ }^{6-14}$

1. Doutorado - docente (CCBS/UAM/Obstetricia) da Universidade Federal de Campina Grande (UFCG) - Campina Grande, PB

2. Doutorado - médica assistente da Clínica Obstétrica da Faculdade de Medicina da Universidade de São Paulo - USP, São Paulo, SP

3. Doutorado - médico assistente da Clínica Obstétrica da Faculdade de Medicina da Universidade de São Paulo - USP, São Paulo, SP

4. Doutorado - médica assistente da Clínica Obstétrica da Faculdade de Medicina da Universidade de São Paulo - USP, São Paulo, SP

5. Doutorado - Livre docência - Professor Titular da Clínica Obstétrica da Faculdade de Medicina da Universidade de São Paulo - USP, São Paulo, SP 
with postnatal follow-up (0-84 months) of euploid fetuses with increased NT and without fetal malformation, and noticed that the level of compromised brain development during childhood ranged from 0 to $8.7 \%$. Nevertheless, only two of these studies used a control group. ${ }^{7,8}$

For that reason, these children should be followed up after birth in order to expand the patient population, especially in the group with NT thicker than $4.5 \mathrm{~mm}$, so as to better define the risk of delayed brain development in cases with normal prenatal screening. ${ }^{6}$ Thus, the present study sought to assess the prenatal and postnatal outcome of cases with increased NT and normal karyotype.

\section{Methods}

This was a prospective study conducted at the Obstetric Outpatient Clinic of Hospital das Clínicas, affiliated with the School of Medicine of Universidade de São Paulo - HC-FMUSP. The study protocol was approved by the local Research Ethics Committee and all assessments were made after a written informed consent was obtained.

Of 6,991 women with live fetuses submitted to an ultrasound scan for detection of chromosomal abnormalities between 11 and 13 weeks and 6 days, 275 fetuses (3.9\%) presented with increased NT.

The technique used to measure NT followed the criteria recommended by the Fetal Medicine Foundation (FMF) London (www.fetalmedicine.com). Fetal morphology in the first trimester was obtained by abdominal examination and complemented by vaginal investigation in cases with inadequate visualization. In the follow-up of cases with increased NT, evaluations were repeated during the 16th week, between the 20th and 24th weeks and between the 32nd and 34th weeks of gestation. Fetal echocardiography was performed from the 12 th week of gestation onwards, and repeated between the 20th and 24th weeks and around the 28th to the 32nd weeks. After birth, these infants underwent careful genetic and echocardiographic evaluation.

NT thickness was considered to be increased when it was above the 95th percentile for the crown-rump length (CRL) according to the curve proposed by Pandya et al. ${ }^{15}$

Fetal karyotyping was established by the cytogenetic analysis of the material obtained from chorionic villus sampling or amniocentesis in 148 cases (53.8\%), by phenotypic analysis in the postnatal period in 98 cases $(35.6 \%)$, but could not be determined in 29 cases (10.5\%) (Eight due to spontaneous abortion, one due to elective termination of pregnancy and 20 due to unknown pregnancy outcome).

An adverse pregnancy outcome was considered when there was natural loss of the prenatal or neonatal conceptus. Spontaneous abortion was regarded as fetal death up to the 20th week of gestation. ${ }^{16}$ Legal abortion was that which was performed after legal approval, considering malformations that precluded extrauterine life. Elective abortion was the one based on the patient's own decision and carried out outside our setting. And fetal death was the death of the conceptus after the $20^{\text {th }}$ week. ${ }^{16}$

The chi-square test or Fisher's exact test was used for comparison of proportions, whereas Student's t test or Mann-Whitney's nonparametric test ${ }^{84}$ was used for comparison of the means. The level of significance was set at $5 \% .{ }^{17}$

\section{RESULTS}

From the sampled 275 gestations of fetuses with increased NT, 29 cases (10.5\%) with unknown karyotypes were excluded. Of the 246 remaining cases, 211 (85.8\%) had normal karyotypes with mean maternal age of 29.6 years (range from 15 to $46, \mathrm{SD}=7$ ) and mean NT of $3.3 \mathrm{~mm}$ (range from 2.5 to 21.5 and $\mathrm{SD}=4.3$ ).

In $88.2 \%(186 / 211)$ of the cases, second-trimester ultrasound scans were performed, of which $75.3 \%$ (140/186) did not show abnormal findings, compared to $24.7 \%$ (46/186) with abnormal results.

Of 46 cases with morphological findings, 30.4\% (14/46) consisted of major malformations, detected in the prenatal or postnatal period, of which $35.7 \%$ (5/14) were cardiac malformations. Morphological analysis was not conducted in $11.8 \%$ (25/211) of cases: eight resulted in abortion, 13 did not turn up for examination and four were lost to follow-up.

As to the presence of major structural malformation it was observed that the group with NT thickness equal to or greater than $4.5 \mathrm{~mm}$ had larger percentage values than other groups, and these percentage values increased as the NT cutoff levels also increased ( $p=0.005$; Fisher's exact test).

Of 186 fetuses submitted to morphological ultrasound examination, the nuchal fold was enlarged in $11.3 \%(21 / 186)$ of cases, with a mean thickness of $4.9 \mathrm{~mm}, \mathrm{SD}=2.1$ and a range from 2 to $20 \mathrm{~mm}$.

A total of $74.9 \%(158 / 211)$ of these cases were submitted to fetal echocardiography in the prenatal or postnatal period. Of this total, 96.8\% (153/158) exhibited normal results, whereas $3.2 \%$ (5/158) showed abnormal echocardiographic findings, despite the fact that $7.0 \%(11 / 158)$ of postnatal examinations, even those which were considered to be normal, yielded minimal findings, without clinical consequences.

The overall pregnancy outcome was known in 196 of 211 cases with normal karyotypes, but $8.1 \%$ (16/196) did not carry pregnancy to full term: $4.6 \%(9 / 196)$ had spontaneous abortion, $2 \%(4 / 196)$ had elective or legal abortion and $1.5 \%$ (3/196) showed intrauterine death. In our patient population, the chance of termination of pregnancy, resulting in fetal or neonatal loss, grew proportionally to the increase in NT. However, this risk was more significant when NT was thicker than $3.5 \mathrm{~mm}$. The estimated odds ratio, when compared to the cases with NT measurement of the 95th percentile at $2.9 \mathrm{~mm}$, amounted to 3.7 when NT measured between 3.0 and $3.4 \mathrm{~mm}$, to 5.8 when it measured between 3.5 and $4.4 \mathrm{~mm}$ and to 61.7 when it was equal to or greater than $4.5 \mathrm{~mm}$. These proportions were significant when NT was thicker than $3.5 \mathrm{~mm}$ ( $p<0.001$; Fisher's exact test).

It was also observed that NT was equal to or greater than 4 $\mathrm{mm}$, being associated with structural malformation or malformation markers, in approximately $40 \%$ of the fetuses that had adverse pregnancy outcomes, mainly spontaneous abortion. 
In the postnatal follow-up, the infant's mean age was 19.7 months, the median was 15 months, the standard deviation was 15.3 months, with a range of 29 days to 72 months.

A total of $72.7 \%(128 / 176)$ of the cases were submitted to postnatal follow-up, and $14.8 \%(19 / 128)$ of the infants had some morphological or functional problem. In $85.2 \%(109 / 128)$ of cases, postnatal follow-up was normal and in 48 cases, telephone contact after childbirth was not possible, or when this was accomplished, the infants did not turn up for evaluation. Table 1 describes the cases with echocardiographic and/or postnatal clinical assessment findings.

The chances of having a liveborn and healthy infant varied according to the measurement of fetal NT, being inversely related to the thickness of NT, amounting to $95.6 \%$ when NT was equal to or greater than the 95th percentile up to $2.9 \mathrm{~mm}, 86.4 \%$ when between 3.0 and $3.4 \mathrm{~mm}, 70.8 \%$ between 3.5 and $4.4 \mathrm{~mm}$ and $37.5 \%$ when equal to or greater than $4.5 \mathrm{~mm}$, as shown in Table 2 .

\begin{tabular}{|c|c|c|}
\hline NT CUTOFF LEVEL & $\begin{array}{l}\text { TOTAL } \\
\text { (n) }\end{array}$ & Normal karyotype \\
\hline \multicolumn{3}{|l|}{$\geq 95^{\circ}$ to 2.9} \\
\hline $\mathrm{Mm}$ & 123 & $109(95.6 \%)$ \\
\hline \multicolumn{3}{|l|}{$3.0-3.4$} \\
\hline $\mathrm{Mm}$ & 57 & $38(86.4 \%)$ \\
\hline \multicolumn{3}{|l|}{$3.5-4.4$} \\
\hline $\mathrm{Mm}$ & 34 & $17(70.8 \%)$ \\
\hline \multicolumn{3}{|l|}{$\geq 4.5$} \\
\hline $\mathrm{Mm}$ & 32 & $6(37.5 \%)$ \\
\hline
\end{tabular}

Table 1. Description of cases with echocardiographic and/or postnatal clinical assessment findings

\begin{tabular}{|c|c|c|c|c|c|}
\hline $\mathrm{N}$ & $\begin{array}{l}\text { NT } \\
(\mathrm{mm})\end{array}$ & $\begin{array}{l}\mathrm{NF} \\
(\mathrm{mm})\end{array}$ & $\begin{array}{l}\text { Age } \\
\text { (months) }\end{array}$ & POSTNATAL ECHO & POSTNATAL CLINICAL ASSESSMENT \\
\hline 01 & 2.5 & NA & 10 & Normal & Macrocephaly \\
\hline 02 & 2.5 & 4.9 & 8 & Normal & $\begin{array}{l}\text { Adrenal hyperplasia epicanthic fold left eye ptosis single } \\
\text { palmar crease } L\end{array}$ \\
\hline 03 & 2.5 & 7.0 & 48 & Mitral valve leakage w/o prolapse & Normal \\
\hline 04 & 2.5 & 5.1 & 10 & Normal & Low-set ears \\
\hline 05 & 2.5 & 6.0 & 15 & Normal & Single palmar crease \\
\hline 06 & 2.5 & 4.0 & 36 & Mild pulmonary dysplasia w/o transvalvar gradient & Normal \\
\hline 07 & 2.5 & 4.5 & 3 & Patent oval foramen & Hyperchromic spot in the nuchal region \\
\hline 08 & 2.6 & 4.1 & 7 & Normal & Postauricular hemangioma \\
\hline 09 & 2.6 & 5.1 & 4 & Normal & Two overlapping toes in the hallux \\
\hline 10 & 2.6 & 5.6 & 50 & Normal & Bilateral clubfoot \\
\hline 11 & 2.7 & 7.0 & 12 & Patent oval foramen & Normal \\
\hline 12 & 2.7 & 6.0 & 20 & $\begin{array}{l}\text { PDA shunt } \\
\text { L-R }\end{array}$ & Elevated T3 \\
\hline 13 & 2.7 & Normal & 19 & Mild thickening of pulmonary valve $w / 0$ gradient & Normal \\
\hline 14 & 2.7 & 4.8 & 24 & Patent oval foramen & Normal \\
\hline 15 & 3.0 & 4.0 & 15 & Normal & Single palmar crease \\
\hline 16 & 3.0 & 5.2 & 29 & Mild pulmonary dysplasia w/o gradient & Normal \\
\hline 17 & 3.0 & 5.4 & 3 & Normal & Congenital L clubfoot \\
\hline 18 & 3.1 & 3.1 & 7 & $\begin{array}{l}\text { Mitral valve failure } \\
\text { w/o clinical consequence }\end{array}$ & Normal \\
\hline 19 & 3.1 & 5.3 & 11 & Normal & Epicanthic fold \\
\hline 20 & 3.1 & 4.5 & 31 & Normal & $\begin{array}{l}\text { Low-set ear sella long philtrum single bilateral palmar } \\
\text { crease epicanthic fold }\end{array}$ \\
\hline 21 & 3.3 & 5.5 & 44 & Normal & Protruding ribs \\
\hline 22 & 3.4 & 5.0 & 15 & Normal & Absence of auricle right auditory canal \\
\hline 23 & 3.9 & 4.3 & 4 & Normal & Low-set left ear \\
\hline 24 & 4.0 & 5.5 & 8 & Mild mitral dysplasia PVS w/o clinical consequence & $\begin{array}{l}\text { Prominent heel rocker-bottom foot anteverted nostrils long } \\
\text { philtrum }\end{array}$ \\
\hline 25 & 6.2 & 8.0 & 8 & Competent mild mitral dysplasia & Normal \\
\hline
\end{tabular}

NOTE: $\mathrm{ECHO}=$ echocardiography; $\mathrm{mm}=$ millimeter; $\mathrm{N}=$ ordinary number; $\mathrm{NF}=$ nuchal fold; $\mathrm{wk}=$ weeks; $\mathrm{NT}=$ nuchal translucency; $\mathrm{US}=\mathrm{ultrasound}$ scanning; $\mathrm{L}=$ left; $\mathrm{L}-\mathrm{R}=$ left to right; $\mathrm{NA}$ $=$ not assessed; $\mathrm{PDA}=$ patent ductus arteriosus; $\mathrm{PVS}=$ pulmonary valvar stenosis; $\mathrm{w} / \mathrm{o}=$ without 


\section{Discussion}

The present study confirms the association between increased NT and structural malformations, especially cardiopathies and adverse pregnancy outcomes.

In the prenatal ultrasonographic follow-up, about one fourth of the cases showed markers or fetal structural malformations, of which one third was regarded as major malformation, with $35.7 \%$ corresponding to heart defects. However, this corroborates the findings of studies that assessed increased NT in fetuses with normal karyotype and found variability in the association with structural malformations, chiefly heart defects, ranging from 4.8 to $32.1 \% .8,10,11,18,19$, In the present study, the chances of major structural malformation, detected in the prenatal period, also grew as NT increased, and therefore proportions were close to the ones described by other authors.1,6,7 Nonetheless, as we observed, most malformations (78.6\%) were detected in the first or second trimester. Malformations that were not diagnosed in the prenatal evaluation (unilateral, bilateral clubfoot and microtia) were isolated cases and were not associated with delayed brain development.

As to the prevalence of major heart defects, the literature demonstrates an exponential increase that is directly related to the increase in NT.1 The present study detected congenital heart defects in $3.2 \%$ of cases, a higher incidence than that observed in the general population (around 1\%),20 but close to the percentage values found by Pandya et al.15 (4\%), and Ghi et al.21 (2.5\%), who used an NT cutoff level equal to or greater than the 95th percentile for the CRL. Several studies were carried out with chromosomally normal fetuses in order to verify the association between increased NT and cardiovascular defects. Recent studies18,22,23 found an overall prevalence of major heart defects similar to the percentage observed in pregnant women with diabetes mellitus, previous child with history of cardiopathy or drug exposure. Therefore, the NT measurement traditionally used to identify fetuses at risk for chromosomal abnormalities can also identify a wide array of fetuses with major cardiac and large vessel malformations, and thus it may be used as a screening method for heart defects in the general population.22 In our study, all malformations were diagnosed during prenatal care, probably because all echocardiograms were performed by a fetal and pediatric echocardiographer. This finding was also observed in other studies, 19 demonstrating the benefit of cardiac evaluation of fetuses with increased NT by an expert.

In the second-trimester morphological assessment, enlarged nuchal fold was observed in $11.3 \%$ of fetuses. Among the fetuses with major malformations, $14.3 \%$ had enlarged nuchal fold. The group with enlarged nuchal fold without any other findings in the ultrasound scan did not show any anomalies in the prenatal or postnatal follow-up. In a study with a larger patient population, adverse outcomes were described in approximately $18.3 \%$ of cases. 2

Recent studies3 corroborate the findings obtained by Pandya et al.,15 who observed $13 \%$ of fetal loss in 565 chromosomally normal fetuses, with an NT equal to or greater than $3 \mathrm{~mm}$, showing that fetal loss rates and survival rates decrease proportionally to the increase in NT thickness, especially when associated with structural malformations. Souka et al.,2 who suggested ultrasonographic monitoring and extra care when assessing the prognosis of gestation of fetuses with increased NT, estimate that only one in every three fetuses with NT equal to or greater than $6.5 \mathrm{~mm}$ progresses to a live birth without structural malformation. So, their conclusion is that pregnancy outcome depends on NT thickness and on its association with fetal structural defects.

Even though increased NT is regarded as a marker of adverse pregnancy outcomes, only a few studies have dealt with the follow-up of liveborn infants, and too few of these studies have followed up children after the age of 5 years.3,7,24,25 Among these studies, we have that of Senat et al., 7 and Bilardo et al., 6 with the largest patient populations, but only the study conducted by Senat et al. 7 included a control group. Bilardo et al6 assessed NT greater than the 95th percentile with normal karyotype and found adverse pregnancy outcomes in $4 \%$ of chromosomally normal fetuses, even with a normal ultrasound scan at 20 weeks. This study concludes that the chance of an infant being born healthy, when the ultrasound scan performed at 20 weeks is normal, amounts to $98 \%$, with a $1.6 \%$ risk of delayed brain development. The study by Senat et al., 7 which assessed the cases of NT greater than the 99th percentile, revealed a high rate of anomalies diagnosed in the postnatal follow-up (around $11.1 \%$ ), half of which were attributed to cardiac malformations, and delayed brain development in two cases ( $1.2 \%$ ), one of them associated with an undefined genetic syndrome and another one with no associated findings.

In our study, postnatal follow-up of infants was normal in $85.2 \%$ and revealed some morphological or functional anomaly in $14.8 \%$. Our results were similar to the ones obtained by Senat et al. 13 despite the fact that we did not observe delayed brain development in our study, probably because we used the 95th percentile as cutoff for NT, with only $19.1 \%$ of cases with NT equal to or greater than the 99th percentile for the CRL. In the present study, the mean age of infants at follow-up was 19.7 months, which may explain the fact that we did not observe any delayed brain development. Likewise, no genetic syndrome was detected in the study by Maymon et al.11 In the studies by 
Pandya et al., 15 only one genetic syndrome was observed, whereas Adekunle et al. 10 found one genetic syndrome and two cases of severe delayed brain development, while Brady et al. 8 detected two cases of genetic syndromes and one case of severe delayed brain development. Therefore, these authors warn about the possible underdiagnosis of delayed brain development because the postnatal follow-up period is confined to the first three years of life. 2

In the postnatal echocardiographic follow-up, we perceived mild cardiac anomalies, without any clinical consequences, in $7 \%$ of children. These findings, although they do not have clinical importance, may be involved in the pathophysiological etiology of increased NT.

Recent studies 3,6,7,26 highlight the necessity of prenatal counseling for parents of chromosomally normal fetuses with NT greater than the 95th percentile and normal fetal morphological examination at 20 weeks, to show that the chance of a favorable pregnancy outcome increases remarkably. However, caution is recommended when the thickness of the nuchal NT is equal to or greater than $6.5 \mathrm{~mm} .6$

\section{Conclusion}

Our study reasserts the necessity of follow-up of chromosomally normal fetuses with increased NT during prenatal care and postnatal follow-up. Similarly to most studies available in the literature,22,27-31 we noted a higher incidence of adverse pregnancy outcomes, 32 fetal structural malformation and findings in the postnatal follow-up. Nevertheless, we know that the counseling of parents of these fetuses is still a limitation, in agreement with Bilardo et al. 6 and Bekker MN,3 who showed that it is not possible to rule out the association with some fetal abnormality, given that, even in the absence of structural malformation in the ultrasound scan, there is increased risk of abortion, of some kind of genetic syndrome or of metabolic disease, conditions that might not be detected during pregnancy. This strengthens the great respect Bilardo et al.33 feel for couples who "having a fetus with increased NT and normal karyotype, cope with a life of uncertainty."

No conflicts of interest declared concerning the publication of this article.

\section{References}

1. Souka AP, Von Kaisenberg CS, Hyett JA, Sonek JD, Nicolaides KH. Increased nuchal translucency with normal Karyotype. Am J Obstet Gynecol. 2005; 192:1005-21.

2. Souka A P, Krampl E, Bakalis S, Heath V, Nicolaides KH. Outcome of pregnancy in chromosomally normal fetuses with increased nuchal translucency in the first trimester. Ultrasound Obstet Gynecol. 2001;18:9-17.

3. Bekker MN. A normal 20-week scan of a euploid fetus with a history of first-trimester increased nuchal translucency: caution or reassurance? Opin Ultrasound Obstet Gynecol. 2007;30:8-10.
4. Nicolaides KH, Spencer K, Avgidou K, Faiola S, Falcon O. Multicenter study of first-trimester screening for trisomy 21 in 75.821 pregnancies: results and estimation of the potential impact of individual riskorientated two-stage first-trimester sceening. Ultrasound Obstet Gynecol. 2005;25:221-6.

5. Brizot ML, Carvalho MHB, Liao AW, Reis SV, Armbruster-Moraes E, Zugaib M. First-trimester screening for chromosomal abnormalities by fetal nuchal translucency in a Brazilian population. Ultrasound Obstet Gynecol. 2001;18:652-5.

6. Bilardo CM, Muller MA, Pajkrt E, Clur SA, Van Zalen MM, Bijlsma EK. Increased nuchal translucency thickness and normal Karyotype: time for parental reassurance. Ultrasound Obstet Gynecol. 2007;30:11-8.

7. Senat MV, Bussieres L, Couderc S, Roume J, Rozenbeg P, Bouyer J, et al. Long-term outcome of children born after a first-trimester measurement of nuchal translucency at the 99th percentile or greater with normal Karyotype: a prospective stdy. Am J Obstet Gynecol. 2007;196:53-6.

8. Brady AF, Pandya PP, Yuksel B, Greenough A, Patton MA, Nicolaides KH. Outcome of chromosomally normal livebirths with increased fetal nuchal translucency at 10 - 14 weeks' gestation. J Med Genet 1998;35:222-4.

9. Van Vugt JMG, Tinnemans BW, Van Zalen-Sprock RM. Outcome and early childhood follow-up of chomosomally normal fetuses with increased nuchal translucency at 10 - 14 week' gestation. Ultrasound Obstet Gynecol. 1998;11:407-9.

10. Adekunle O, Gopee A, El-Sayed M, Thilaganathan B. Increased first trimester nuchal translucency: pregnancy and infant outcomesafter routinescreening for Down's syndrome in an unselected antenatal population. Br J Radiol. 1999; 72:457-60.

11. Maymon R, Jauniaux E, Cohen O, Dreazen E, Weinraub Z, Herman A. Pregnancy outcome and infant follou-up of fetuses with abnormally increased first trimester nuchal translucency. Hum Reprod. 2000; 15:2023-7.

12. Hiippala A, Eronen M, Taipale P, Salonen R, Hiilesmaa V. Fetal nuchal translucency and normal chromosomes: a long-term follow-up study. UItrasound Obstet Gynecol. 2001;18:18-22.

13. Senat MV, De Keersmaecker B, Audibert F, Montcharmont G, Frydman R, Ville Y. Pregnancy outcome in fetuses with increased nuchal translucency and normal Karyotype. Prenat Diagn. 2002;22:345-49.

14. Cheng CC, Bahado-Singh RO, Chen SC, Tsai MS. Pregnancy outcomes with increased nuchal translucency after routine Down syndrome screening. Int J Gynaecol Obstet. 2004;84:5-9.

15. Pandya PP, Kondylios A, Hilbert L, Snijders RJ, Nicolaides KH. Chromosomal defects and outcome in 1015 fetuses with increased nuchal translucency. Ultrasound Obstet Gynecol. 1995;5:15-9.

16. Rezende J. Obstetrícia. 8ª ed. Rio de Janeiro: Guanabara Koogan; 1998. Cap. 55.

17. Rosner B. Fundamentals of biostatistics 2th ed. Boston. PWS; 2000.

18. Lopes LM, Brizot ML, Lopes MA, Ayello VD Schultz R, Zugaib M. Structural and functional cardiac abnormalities identified prior to 16 weeks' gestation in fetuses with increased nuchal translucency. Ultrasound Obstet Gynecol. 2003;22:470-8

19. Bilardo CM, Pajkrt E, Graaf I, Mol BW, Bleker OP. Outcome of fetuses with enlarged nuchal translucency and normal karyotype. Ultrasound Obstet Gyneacol. 1998;11:401-6.

20. Hoffman JIE. Incidence of congenital heart disease: I. Postnatal incidence. Pediatr Cardiol. 1995;16:103-13.

21. Ghi T, Huggon IC, Zosmer N, Nicolaides KH. Incidence of major structural cardiac defects associated with increased nuchal translucency but normal karyotype. Ultrasound Obstet Gynecol. 2001;18:610-4.

22 Hyett J, Perdu M, Sharland G, Snijders RJM, Nicolaides KH. Using fetal nuchal translucency to screen for major congenital cardiac defects at 10-14 weeks of gestation: population based cohort study. BMJ. 1999;318:81-5.

23. McAuliffe F, Winsor S, Hornberger L, Johnson JA. Fetal cardiac defects and increased nuchal translucency thickness: a prospective study. Am J Obstet Gynecol. 2004;191:1486-90. 
24. Spencer K, Cowans NJ, Avgidou K, Nicolaides KH. First-trimester ultrasound and biochemical markers of aneuploidy and the prediction of impending fetal death. Ultrasound Obstet Gynecol. 2006;28:637-43.

25. Westin M, Saltvedt S, Almstrom H, Grunewald C, Valentin L. By how much does increased nuchal translucency increased the risk of adverse pregnancy outcome in chromosomally normal fetuses? A study of 16260 fetuses derived from an unselected pregnant population. Ultrasound Obstet Gynecol. 2007;29:150-8.

26. Kypros H. Nicolaides, MD. Nuchal translucency and other first-trimester sonographic markers of chromosomal abnormalities. Am J Obstet Gynecol. 2004;191:45-67.

27. Carvalho MHB, Brizot ML, Lopes LM, Chiba CH, Miyadahira S, Zugaib M Detection of fetal structural abnormalities at the 11 - 14 weeks ultrasound scan. Prenat Diagn. 2002;22:1-4

28. Snijders RJM, Johnson S, Sebire NJ, Noble PL, Nicilaides KH. First-trimester ultrasound screening for chromosomal defects [Review]. Ultrasound Obstet Gynecol. 1996;7:216-6.

29. Iskaros J, Jauniaux E, Rodeck C. Outcome of nonimmune hidrops fetalis diagnosed during the first half of pregnancy. Obstet Gynecol. 1997;90:321-5.
30. Matias A, Huggon I, Areias JC Montenegro N, Nicolaides KH. Cardiac defects in chromosomally normal fetuses with abnormal ductus venosus blood flow at 10 - 14 weeks. Ultrasound Obstet Gynecol. 1999;14:307-10.

31. Dane B, Dane C, Cetin A, Kiray M, Sivri D, Yayla M. Pregnancy outcome in fetuses with increased nuchal translucency. J Perinatol. 2008;28:400-4.

32. Piazze J, Anceschi MM, Cerekja A, La Torre R, Pala A, Papa A, et al. Nuchal translucency as a predictor of adverse pregnancy outcome. 2007;98:5-9.

33. Bilardo CM. increased nuchal translucency and normal karyotype: coping with uncertainty. Ultrasound Obstet Gynecol. 2001;17:99-101.

Artigo recebido: 3/11/08

Aceito para publicação: 17/3/09 